\title{
Theophylline improves acute mountain sickness
}

\author{
R. Fischer*, S.M. Lang*, U. Steiner*, M. Toepfer*, H. Hautmann*, H. Pongratz**, R.M. Huber*
}

Theophylline improves acute mountain sickness. R. Fischer, S.M. Lang, U. Steiner, M. Toepfer, H. Hautmann, H. Pongratz, R.M. Huber. (C)ERS Journals Ltd 2000.

ABSTRACT: A randomized two-part study was conducted in order to determine the efficacy of theophylline in the treatment of acute mountain sickness during fast ascent to altitudes $>2,500 \mathrm{~m}$.

Fourteen healthy male subjects participated in a randomized single-blind placebocontrolled crossover study carried out in a decompression chamber (simulated altitude $4,500 \mathrm{~m}$ ). A second randomized single-blind, placebo-controlled study was conducted at a high-altitude research laboratory $(3,454 \mathrm{~m})$ and included 21 healthy male subjects. The study medication was either $375 \mathrm{mg}$ oral slow-release theophylline (250 $\mathrm{mg}$ if $<70 \mathrm{~kg}$ ) or a matched placebo tablet taken twice daily. The acute mountain sickness score (AMSS) was assessed three times a day, beginning $18 \mathrm{~h}$ prior to altitude exposure and continuing for $18 \mathrm{~h}$ after altitude exposure. In addition, measurements of respiratory frequency, pulse rate, oxygen saturation and arterial blood gas levels were performed.

Acute mountain sickness was significantly reduced by theophylline during the decompression chamber study (mean $\pm S D$ 1.2 \pm 0.9 ) with placebo versus $3.6 \pm 0.8$ with theophylline; $p=0.03)$. During the high-altitude study, subjects with theophylline showed a significantly lower AMSS on arrival and after $18 \mathrm{~h}$ at altitude $(0.6$ versus 2.3 , $p=0.03$ ). Oxygenation was improved in both parts of the study.

In conclusion, oral slow-release theophylline improves acute mountain sickness. Eur Respir J 2000; 15: 123-127.
*Dept of Medicine, Division of Pneumology, Klinikum Innenstadt, University of Munich and $* *$ Medical Institute of the Air Force, Fürstenfeldbruck, Germany.

Correspondence: R. Fischer, Pneumology Medizinische Klinik, Klinikum Innenstadt LMU, München Ziemssenstr. 1 D-80336 München. Fax: 498951604905

Keywords: Acute mountain sickness high altitude

oxygenation

prevention

theophylline

Received: March 311999

Accepted after revision September 91999

This study was supported, in part, by Byk Gulden, Constance, Germany.
Acute mountain sickness (AMS) is a frequent medical disorder in travellers who rapidly ascend to altitudes $>2,500$ $\mathrm{m}$ [1]. When altitudes $>4,000 \mathrm{~m}$ are reached within hours, only few do not have at least mild symptoms. The symptoms of mild AMS include headache, dizziness, fatigue, gastrointestinal symptoms and sleep disturbance. During prolonged stay at high altitude, symptoms improve usually within 24-48 h.

The pathogenesis of AMS is not fully understood, but it is generally agreed that the main underlying cause is hypoxia, which initiates the pathogenetic processes leading to AMS. Hypoxia is thought to cause water retention or a shift of water from intracellular to extracellular compartments [2], increase microvascular permeability [3] and increase cerebral blood flow [4]. All of these factors may contribute to AMS, although the role of enhanced cerebral blood flow remains controversial [5].

AMS is normally best prevented by ascending slowly to high altitude. However, when rapid ascent is necessary (i.e. during rescue operations or passive transportation to high altitude), medical prophylaxis may be indicated. Acetazolamide at a dose of $250 \mathrm{mg}$ twice daily and dexamethasone at doses of $>4 \mathrm{mg}$ twice daily have been reported effective in the preventive treatment of AMS $[6,7]$.

The effects of theophylline on AMS have not been studied, although its pharmacological profile would seem to predispose this substance to the treatment of AMS. The multiple pharmacological effects of theophylline (a phosphodiesterase inhibitor) are well characterized, and comprise a decrease in cerebral blood flow [8], suppression of microvascular permeability in the brain and lungs [9], a bronchodilating effect [10], central respiratory stimulation [11], a decrease in pulmonary arterial pressure [12], inhibition of inflammatory mediators [13], a reduction in periodic breathing [14], improved diaphragmatic contractility [15], and induction of mild diuresis.

The purpose of this randomized single-blind study was to examine the effects of oral slow-release theophylline on AMS and blood oxygenation in a group of healthy male subjects during fast ascent to altitudes $>3,500 \mathrm{~m}$ during an investigation carried out in a decompression chamber and during an excursion to the Jungfranjoch (Switzerland).

\section{Materials and methods}

\section{Study population}

All subjects gave informed consent to participation in the study, and the study protocol was approved by the local ethics committee. They were selected from a group of healthy mountaineers. Exclusion criteria for both studies were 1) female sex, to avoid a possible sex difference in susceptibility to AMS [16], 2) smoking, 3) noncompliance with the study protocol 4) previous pulmonary disease, and 5) concomitant medication. The criteria for entering 
the study were: 1) normal weight (body mass index (BMI) $<25$ ), and 2) a medical history of constant good health.

There were no significant differences in both studies regarding mean $\pm \mathrm{SD}$ age $(29 \pm 8$ yrs in the decompression chamber study versus $29 \pm 8$ yrs in the high-altitude study) and BMI $(21 \pm 3$ in the decompression chamber study versus $21 \pm 2$ in the high-altitude study).

\section{Study design}

The first part of the study (decompression chamber study) was performed in a decompression chamber at the medical institute of the air force near Munich (Fürstenfeldbruck, Germany). The crossover study had a randomized singleblind placebo-controlled design, with an interval of 3 weeks between the two chamber sessions. The chamber was decompressed for a total of $7 \mathrm{~h}$ to reach a simulated altitude of 4,500 $\mathrm{m}(14,850 \mathrm{ft})$; this altitude was reached within 30 min. Fourteen subjects were randomly allocated to placebo or study medication for the first session and medication was cross-changed after the 3 weeks interval, for the second session.

The second part of the study (high-altitude study) was carried out at the High Altitude Study Laboratory, Jungfraujoch, Switzerland at 3,454 m (11,320 ft). Twenty-one subjects were randomly allocated to placebo or study medication and were transported by rail within $3 \mathrm{~h}$ to the Jungfraujoch and stayed there for $\geq 36 \mathrm{~h}$ without physical exercise.

\section{Study medication}

For the decompression chamber study, subjects were randomly allocated to placebo or study medication and started taking the tablets 3 days before entering the chamber. The study medication was $375 \mathrm{mg}$ oral slow-release theophylline taken twice daily (Euphylong; Byk Gulden, Constance, Germany) or $250 \mathrm{mg}$ twice daily for subjects weighing $<70 \mathrm{~kg}$ or matched placebo tablets twice daily. The study medication was stopped immediately after the experiment. After a 3-week interval, the medication was cross-changed and started 3 days before the second measurements were performed.

In the high-altitude study, subjects were randomly allocated to placebo or study medication, starting 3 days before the journey to Jungfraujoch, at the same doses as used in the decompression chamber study. Theophylline intake was stopped $12 \mathrm{~h}$ after arrival at altitude in order to investigate possible rebound effects.

\section{Measurements}

In both studies, all subjects completed a diary card recording symptoms included in the acute mountain sickness score (AMSS, Lake Louise version [17]) three times a day, beginning $18 \mathrm{~h}$ before and continuing for $18 \mathrm{~h}$ after altitude exposure. In the decompression chamber study, AMSS was additionally measured at 0,210 and $420 \mathrm{~min}$ of exposure to hypobaric hypoxia. The questions related to the following symptoms: headache, gastrointestinal symptoms, fatigue/weakness and dizziness/light-headedness. The item "difficulty sleeping" was included during the high-altitude study. As not much activity was possible during the decompression chamber study, the question "reduction of activities" was not included in the question- naire. Each symptom was scored from 0 (none) to 3 (severe). The overall score was then calculated by addition of each individual parameter score.

In both studies, measurements of respiratory frequency, pulse rate and oxygen saturation were performed by means of pulse oximetry (OXY3; Radiometer, Copenhagen, Denmark). For technical reasons, arterial blood gas levels could only be measured in eight subjects during the decompression chamber study and transcutaneous oxygen $\left(P \mathrm{tc}, \mathrm{O}_{2}\right)$ and carbon dioxide tension $\left(P \mathrm{tc}, \mathrm{CO}_{2}\right)(\mathrm{ABL} 5$ and TCM3; Radiometer) only in nine subjects during the high-altitude study.

Samples for serum theophylline level determination were taken $6 \mathrm{~h}$ after the last intake of medication, the samples were processed immediately and frozen at $-20^{\circ} \mathrm{C}$ until assayed. Measurement of theophylline levels was performed using an enzyme immunoassay technique (CEDIA $®$ ) Theophylline II; Boehringer Mannheim, Indianapolis, IN, USA).

\section{Data analysis}

Data were analysed using SPSS software (release 8.0; SPSS, Inc. Chicago, IL, USA). Independent (high-altitude study) and paired (decompression chamber study) t-tests were used to compare blood gas parameters, respiratory frequency, pulse rate and serum theophylline levels; analysis of variance procedures and the Bonferroni post hoc test were used to compare time-dependent effects. The Wilcoxon signed-rank test with exact procedures (decompression chamber study) and the Mann-Whitney U-test with exact procedures (high-altitude study) were used to compare overall treatment effects on the AMSS and treatment effects at different time intervals. A p-values of $<0.05$ was regarded as significant.

\section{Results}

The mean serum theophylline levels were $40.5 \pm 28.3 \mu \mathrm{m}$ in the decompression chamber study and 51.6 $\pm 4.4 \mu \mathrm{m}$ in the high-altitude study. Theophylline dosing was generally well tolerated, apart from in four subjects who suffered tachycardia and difficulty sleeping. Subjects experiencing side-effects reduced their theophylline intake and demonstrated lower serum theophylline levels. In the decompression chamber study, four subjects reduced their intake of theophylline tablets due to sleeplessness and tachycardia, and one subject suffered from tremors. In the presence of theophylline side-effects, low serum theophylline levels (as low as $18.9 \mu \mathrm{m}$ ) were accepted as effective in these individuals.

The two study groups participating in the decompression chamber study did not differ in baseline mean arterial oxygen saturation $\left(\mathrm{Sa}_{2} \mathrm{O}_{2}\right), P \mathrm{tc}, \mathrm{O}_{2}$, and $P \mathrm{tc}, \mathrm{CO}_{2}$ respiratory frequencies and pulse rates. Statistically significant differences in pulse rate and $\mathrm{Sa}_{\mathrm{a}} \mathrm{O}_{2}$ could be demonstrated at 210 min (table 1). Slow-release theophylline given during exposure to acute hypobaric hypoxia resulted in a marked improvement in the AMSS as compared to that found in subjects taking matched placebo (table 2).

During the high-altitude study, both study groups did not differ significantly on arrival and after $36 \mathrm{~h}$ in their cardiopulmonary parameters (table 3 ). The placebo-treated 
Table 1. - Comparison of cardiopulmonary parameters during the decompression chamber study in subjects taking theophylline or placebo

\begin{tabular}{|c|c|c|c|c|c|}
\hline & \multirow[b]{2}{*}{ Time } & \multirow[b]{2}{*}{$\begin{array}{c}\text { Subjects } \\
\mathrm{n}\end{array}$} & \multicolumn{2}{|c|}{ Group } & \multirow[b]{2}{*}{$\mathrm{p}$-value } \\
\hline & & & Theo & $\mathrm{P}$ & \\
\hline \multirow[t]{2}{*}{$\mathrm{S}_{\mathrm{a}, \mathrm{O}_{2}} \%$} & Baseline & 14 & $97 \pm 2$ & $97 \pm 2$ & 0.51 \\
\hline & $210 \mathrm{~min}$ & 14 & $84 \pm 4$ & $81 \pm 5$ & 0.01 \\
\hline \multirow{2}{*}{$P \mathrm{tc}, \mathrm{O}_{2} \mathrm{kPa}$} & Baseline & 8 & $11 \pm 0.9$ & $11 \pm 0.9$ & 0.46 \\
\hline & $300 \mathrm{~min}$ & 8 & $6 \pm 0.9$ & $6 \pm 0.4$ & 0.31 \\
\hline \multirow{2}{*}{$P_{\mathrm{tc},} \mathrm{O}_{2} \mathrm{kPa}$} & Baseline & 8 & $5 \pm 0.3$ & $5 \pm 0.4$ & 0.84 \\
\hline & $300 \mathrm{~min}$ & 8 & $4 \pm 0.6$ & $5 \pm 0.3$ & 0.47 \\
\hline$f \mathrm{R}$ & Baseline & 14 & $15 \pm 2$ & $13 \pm 3$ & 0.18 \\
\hline breath $\cdot \min ^{-1}$ & $210 \mathrm{~min}$ & 14 & $16 \pm 5$ & $15 \pm 5$ & 0.67 \\
\hline \multirow{2}{*}{$\begin{array}{l}\text { Pulse rate } \\
\text { beats } \cdot \mathrm{min}^{-1}\end{array}$} & Baseline & 14 & $74 \pm 7$ & $71 \pm 8$ & 0.47 \\
\hline & $210 \mathrm{~min}$ & 14 & $86 \pm 15$ & $81 \pm 12$ & 0.03 \\
\hline
\end{tabular}

Data are presented as mean \pm SD. Theo: theophylline; P: placebo; $\mathrm{Sa}, \mathrm{O}_{2}$ : arterial oxygen saturation; $P \mathrm{tc}, \mathrm{O}_{2}$ : transcutaneous oxygen tension; $P \mathrm{tc}, \mathrm{O}_{2}$ : transcutaneous carbon dioxide tension; $f \mathrm{R}$ : respiratory frequency.

group showed a rapid increase in AMSS during the first 6 $\mathrm{h}$ at 3,454 $\mathrm{m}$ (table 4). In the following hours (up to $36 \mathrm{~h}$ ), there was a steady decline in AMSS, reaching baseline values after $36 \mathrm{~h}$. In the theophylline-treated group, the AMSS increased during the first $6 \mathrm{~h}$ and decreased during the following $12 \mathrm{~h}$. Twelve hours after cessation of theophylline intake (12 $\mathrm{h}$ after arrival) there was a rebound of AMS (at 24-30 h). The comparison between both study groups showed that there was a statistically significant difference between treated and control individuals at 0 and $18 \mathrm{~h}$ at high altitude. At $6 \mathrm{~h}$ after arrival at Jungfraujoch, the difference in AMSS's did not reach statistical significance, but there was a marked trend indicating a positive effect of theophylline. At $12 \mathrm{~h}$, the same trend could be observed, when the symptom "difficulty sleeping" was omitted from analysis (mean rank placebo 13.2 versus theophylline $8.6 ; \mathrm{p}=0.09$ ). This symptom could not be reliably assessed at 6-h intervals as most participants slept between 12 and $18 \mathrm{~h}$ but none slept between 0 and $12 \mathrm{~h}$ after arrival at Jungfraujoch.

\section{Discussion}

The two parts of the study showed independently that oral slow-release theophylline improves AMS, when subjects are exposed to acute hypobaric hypoxia.

The mechanisms leading to the development of AMS are not yet clear, but it has been shown that increasing cerebral oedema and increased cerebral blood flow are associated with this condition $[2,4,5]$. Owing to these changes, headache is the leading symptom of AMS, which was confirmed in the present study. Theophylline reduces cerebral blood flow, probably by acting directly through inhibition of endothelial factors (e.g. adenosine) [18], although the exact cellular mechanisms of theophylline action remain elusive [19]. This effect could be beneficial in the prevention and treatment of patients with AMS. In the present subjects, theophylline was able to reduce the development of headache during both parts of the study. Interestingly, after stopping intake of theophylline during the high-alti-
Table 2. - Reduction in acute mountain sickness score (AMSS) with theophylline during the decompression chamber study

\begin{tabular}{lcccc}
\hline & \multicolumn{4}{c}{ AMSS } \\
\cline { 2 - 5 } Time-point & Subjects n & Theophylline & Placebo & p-value \\
\hline Baseline & 14 & $1.4 \pm 1.5$ & $1.4 \pm 1.0$ & 0.78 \\
$210 \mathrm{~min}$ & 14 & $1.2 \pm 0.9$ & $3.6 \pm 0.8$ & 0.03 \\
$420 \mathrm{~min}$ & 14 & $2.6 \pm 2.2$ & $4.1 \pm 2.3$ & 0.11 \\
\hline
\end{tabular}

Data are presented as mean \pm SD.

tude study, a slight rebound of AMS (mainly headache) was found.

Decreased microvascular permeability may be another beneficial effect of theophylline, accounting for the better performance observed in the subjects taking theophylline after acute exposure to high altitude [20]. Hypoxia induces microvascular permeability within the pulmonary vessels [21], an effect which is probably also present in cerebral vessels. In this context, theophylline and dexamethasone could act in an additive way in the prevention of AMS.

Additional mechanisms may explain the beneficial effects of oral-slow release theophylline on the development of AMS. Among them, dose-dependent bronchodilatation leads to improvement of ventilatory patterns and reduces trapped air. In patients with chronic obstructive pulmonary disease, theophylline was shown to improve oxygenation as well as the forced expiratory volume in one second $[15$, 22]. Similar effects can be expected in subjects acutely exposed to hypobaric hypoxia [23]. Furthermore, theophylline is able to improve central respiratory drive and, therefore, to stimulate a blunted hypoxic ventilatory response in AMS-susceptible subjects [24]. This is supported by the present data, which show that the respiratory frequency was higher in subjects on theophylline compared to the placebo group, although these data did not reach statistical significance. As this increase in ventilation and, therefore, in oxygenation was not pronounced in the treatment group, this seems not to be the main mechanism of action in reducing AMS. By contrast, acetazolamide is

Table 3. - Comparison of cardiopulmonary parameters during the high-altitude study in subjects taking theophylline or placebo

\begin{tabular}{|c|c|c|c|c|c|}
\hline & \multirow[b]{2}{*}{ Time } & \multirow[b]{2}{*}{$\begin{array}{l}\text { Subjects } \\
\text { n }\end{array}$} & \multicolumn{2}{|c|}{ Group } & \multirow[b]{2}{*}{ p-value } \\
\hline & & & Theo & $\mathrm{P}$ & \\
\hline \multirow{2}{*}{$\mathrm{Sa}_{\mathrm{a}, \mathrm{O}_{2}} \%$} & Arrival & 21 & $90 \pm 1$ & $87 \pm 3$ & 0.06 \\
\hline & After $36 \mathrm{~h}$ & 10 & $90 \pm 3$ & $89 \pm 2$ & 0.34 \\
\hline \multirow{2}{*}{$\mathrm{Ptc}, \mathrm{O}_{2} \mathrm{kPa}$} & Arrival & 9 & $8 \pm 1.4$ & $6 \pm 1.0$ & 0.09 \\
\hline & After $36 \mathrm{~h}$ & 9 & $7 \pm 0.7$ & $8 \pm 1.7$ & 0.06 \\
\hline \multirow[t]{2}{*}{$\mathrm{Ptc}, \mathrm{CO}_{2} \mathrm{kPa}$} & Arrival & 9 & $4 \pm 0.8$ & $4 \pm 0.7$ & 0.49 \\
\hline & After $36 \mathrm{~h}$ & 9 & $5 \pm 0.6$ & $5 \pm 0.5$ & 0.82 \\
\hline$f \mathrm{R}$ & Arrival & 21 & $14 \pm 3$ & $13 \pm 4$ & 0.66 \\
\hline breath $\cdot \min ^{-1}$ & After $36 \mathrm{~h}$ & 21 & $16 \pm 4$ & $13 \pm 3$ & 0.14 \\
\hline \multirow{2}{*}{$\begin{array}{l}\text { Pulse rate } \\
\text { beats } \cdot \mathrm{min}^{-1}\end{array}$} & Arrival & 21 & $92 \pm 5$ & $91 \pm 7$ & 0.70 \\
\hline & After $36 \mathrm{~h}$ & 21 & $86 \pm 8$ & $90 \pm 10$ & 0.36 \\
\hline
\end{tabular}

Data are presented as mean \pm SD. Theo: theophylline; P: placebo; $\mathrm{Sa}_{\mathrm{a}} \mathrm{O}_{2}$ : arterial oxygen saturation; $\mathrm{Ptc}, \mathrm{O}_{2}$ : transcutaneous oxygen tension; $P \mathrm{tc}, \mathrm{CO}_{2}$ : transcutaneous carbon dioxide tension; $f \mathrm{R}$ : respiratory frequency. 
Table 4. - Reduction in acute mountain sickness score (AMSS) with theophylline during the high-altitude study

\begin{tabular}{lcccc}
\hline & \multicolumn{4}{c}{ AMSS } \\
\cline { 2 - 5 } $\begin{array}{l}\text { Time-point } \\
\mathrm{h}\end{array}$ & $\begin{array}{c}\text { Subjects } \\
\mathrm{n}\end{array}$ & Theophylline & Placebo & $\mathrm{p}$-value \\
\hline-6 & 21 & $1.2 \pm 2.1$ & $1.6 \pm 1.3$ & 0.23 \\
0 & 21 & $1.0 \pm 2.0$ & $2.7 \pm 1.6$ & 0.01 \\
6 & 21 & $3.3 \pm 3.7$ & $4.9 \pm 3.4$ & 0.25 \\
12 & 21 & $2.0 \pm 2.5$ & $3.2 \pm 2.5$ & 0.23 \\
18 & 21 & $0.6 \pm 0.8$ & $2.3 \pm 2.0$ & 0.03 \\
24 & 21 & $2.6 \pm 2.7$ & $1.6 \pm 1.2$ & 0.65 \\
30 & 21 & $2.1 \pm 2.2$ & $0.8 \pm 1.1$ & 0.29 \\
36 & 21 & $1.2 \pm 1.4$ & $1.0 \pm 1.4$ & 0.53 \\
42 & 21 & $1.7 \pm 0.8$ & $0.5 \pm 0.8$ & 0.14 \\
\hline
\end{tabular}

Data are presented as mean \pm SD.

thought to be a strong respiratory stimulant due to its inhibition of carbonic anhydrase. It has been shown to increase ventilation and arterial oxygen tension during daytime and sleep at high altitude [25-27], thereby reducing AMS.

Other mechanisms of action of theophylline under discussion are the reduction in pulmonary arterial tension and improvement in right and left ventricular ejection fraction. This might also be an additional beneficial effect of theophylline. Whether theophylline could be used to reduce the incidence of high-altitude pulmonary oedema remains to be studied.

Currently there are two other substances which may be effective in the prevention and treatment of AMS: acetazolamide and dexamethasone $[6,26,28]$. Therefore, the question arises as to whether there is a need for additional medication. However, both acetazolamide and dexamethasone have a number of side-effects, limiting their widespread applicability. Theophylline could be a safe alternative for subjects with contra-indications for acetazolamide or dexamethasone. Its safety was a matter of concern for a long time, but, recently, it has been accepted as being a safe and welltolerated drug [19]. The side-effects are dose-dependent and, in most cases, preventable by slow increase of the dose. In the small group of healthy mountaineers, mild side-effects were noted. Thus, the uncontrolled use of theophylline by the general public on high-altitude trekking holidays cannot be recommended without medical supervision. However, in subjects with asthma or mild chronic obstructive pulmonary disease, theophylline might be superior to acetazolamide [27].

In conclusion, the present data show that oral slowrelease theophylline is an effective treatment for acute mountain sickness. However, it should be kept in mind that the use of drugs for the prevention of acute mountain sickness should be limited to circumstances in which rapid ascent to high altitude is unavoidable. It should not replace slow but physiological adaptation to hypobaric hypoxia.

\section{References}

1. Hackett PH, Rennie D. The incidence, importance, and prophylaxis of acute mountain sickness. Lancet 1976; 2: 1149-1155.

2. Hackett PH, Rennie D, Grover RF, Reeves JT. Acute mountain sickness and the edemas of high altitude: a common pathogenesis? Respir Physiol 1981; 46: 383390.

3. Chryssanthou C, Palaia T, Goldstein G, Stenger R. Increase in blood-brain barrier permeability by altitude decompression. Aviat Space Environ Med 1987; 58: 1082-1086.

4. Otis SM, Rossman ME, Schneider PA, Rush MP, Ringelstein EB. Relationship of cerebral blood flow regulation to acute mountain sickness. $J$ Ultrasound Med 1989; 8: 143-148.

5. Baumgartner RW, Bartsch P, Maggiorini M, Waber U, Oelz O. Enhanced cerebral blood flow in acute mountain sickness. Aviat Space Environ Med 1994; 65: 726-729.

6. Ellsworth AJ, Meyer EF, Larson EB. Acetazolamide or dexamethasone use versus placebo to prevent acute mountain sickness on Mount Rainier. West J Med 1991; 154: 289-293.

7. Rock PB, Johnson TS, Larsen RF, Fulco CS, Trad LA, Cymerman A. Dexamethasone as prophylaxis for acute mountain sickness. Effect of dose level. Chest 1989; 95: 568-573.

8. Morii S, Ngai AC, Ko KR, Winn HR. Role of adenosine in regulation of cerebral blood flow: effects of theophylline during normoxia and hypoxia. Am J Physiol 1987; 253: H165-H175.

9. Persson CC. The role of microvascular permeability in the pathogenesis of asthma. Eur J Respir Dis Suppl 1986; 144: 190-216.

10. Rabe KF, Magnussen H, Dent G. Theophylline and selective PDE inhibitors as bronchodilators and smooth muscle relaxants. Eur Respir J 1995; 8: 637-642.

11. Lakshminarayan S, Sahn SA, Weil JV. Effect of aminophylline on ventilatory responses in normal man. Am Rev Respir Dis 1978; 117: 33-38.

12. Lejeune P, Leeman M, Melot C, Naeije R. Effects of theophylline and S 9795 on hyperoxic and hypoxic pulmonary vascular tone in intact dogs. Eur Respir J 1989; 2: 370-376.

13. Finnerty JP, Lee C, Wilson S, Madden J, Djukanovic R, Holgate ST. Effects of theophylline on inflammatory cells and cytokines in asthmatic subjects: a placebo controlled parallel group study. Eur Respir J 1996; 9: 1672-1677.

14. Hudgel DW, Thanakitcharu S. Pharmacologic treatment of sleep-disordered breathing. Am J Respir Crit Care Med 1998; 158: 691-699.

15. Murciano D, Aubier M, Lecocguic Y, Pariente R. Effects of theophylline on diaphragmatic strength and fatigue in patients with chronic obstructive pulmonary disease. $N$ Engl J Med 1984; 311: 349-353.

16. Kayser B. Acute mountain sickness in western tourists around the thorong pass $(5400 \mathrm{~m})$ in Nepal. $J$ Wild Med 1991; 2: 110-117.

17. Roach RC, Bärtsch P, Oelz O, Hackett PH. The Lake Louise acute mountain sickness scoring system. In: Sutton JR, Houston CS, Coates G, eds. Hypoxia and Molecular Medicine. Burlington, VT, Queen City Press, 1993; pp. 272-274.

18. Bowton DL, Haddon WS, Prough DS, Adair N, Alford PT, Stump DA. Theophylline effect on the cerebral blood flow response to hypoxemia. Chest 1988; 94: 371-375.

19. Milgrom H, Bender B. Current issues in the use of theophylline. Am Rev Respir Dis 1993; 147: S33-S39.

20. Kerttula T, Kaukinen S, Seppala E, et al. Theophylline infusion modulates prostaglandin and leukotriene production in man. Prostaglandins Leukot Essent Fatty Acids 1997; 57: 555-560.

21. Schoene RB, Swenson ER, Pizzo CJ, et al. The lung at 
high altitude: bronchoalveolar ravage in acute mountain sickness and pulmonary edema. J Appl Physiol 1988; 64: 2605-2613.

22. Mulloy E, McNicholas WT. Theophylline improves gas exchange during rest, exercise, and sleep in severe chronic obstructive pulmonary disease. Am Rev Respir Dis 1993; 148: 1030-1036.

23. Welsh CH, Wagner PD, Reeves JT, et al. Operation Everest II: Spirometric and radiographic changes in acclimatized humans at simulated high altitudes. Am Rev Respir Dis 1993; 147: 1239-1244.

24. Darnall RA Jr. Aminophylline reduces hypoxic ventilatory depression: possible role of adenosine. Pediatr Res 1985; 19: 706-710.
25. Sutton JR, Houston CS, Mansell AL, et al. Effect of acetazolamide on hypoxemia during sleep at high altitude. N Engl J Med 1979; 301: 1329-1331.

26. Grissom CK, Roach RC, Sarnquist FH, Hackett PH. Acetazolamide in the treatment of acute mountain sickness: clinical efficacy and effect on gas exchange. Ann Intern Med 1992; 116: 461-465.

27. Mirrakhimov M, Brimkulov N, Cieslicki J, et al. Effects of acetazolamide on overnight oxygenation and acute mountain sickness in patients with asthma. Eur Respir $J$ 1993; 6: 536-540.

28. Hackett PH, Roach RC, Wood RA, et al. Dexamethasone for prevention and treatment of acute mountain sickness. Aviat Space Environ Med 1988, 59: 950-954. 